\title{
Improving Rutting Resistance of Flexible Pavement Using Geosynthetics
}

\author{
Ahmed Ebrahim Abu El-Maaty \\ Faculty of Engineering, Civil Engineering Department, Menoufia University, Shibin Elkom, Egypt \\ Email: maaty5000@yahoo.com
}

Received 14 April 2016; accepted 20 May 2016; published 23 May 2016

Copyright (c) 2016 by author and OALib.

This work is licensed under the Creative Commons Attribution International License (CC BY). http://creativecommons.org/licenses/by/4.0/

(c) () D Den Access

\begin{abstract}
Unbound base layers deform under load and contribute to the accumulation of ruts. Therefore, this study was concerned with studying the effect of reinforcement on the behavior of unbound granular material that used in flexible pavement layers as a base course. Two main geothynthetic types were used in this study. These types were woven geotextile and geogrid. Two geogrid opening sizes were used (GR105 and GR420). The experimental work was designed to evaluate plastic and elastic deformation and the modulus of elasticity of reinforced limestone base course. This experimental work carried out utilizing the static plate loading test in a test-model which simulated the subgrade and base course of the flexible pavement. The effect of base thickness, geogrid depth, modulus of elasticity of base course and geogrid edges fixation on the deformation characteristics were studied. Furthermore, the effect of loading time on the accumulated deformation was investigated. Moreover, the effect of reinforcement on base thickness saving (BCR) and deformation reduction ratio (DRR) was studied. A great influence for reinforcement especially with geogrid (GR420) was observed in improving the deformation characteristics of base course.
\end{abstract}

\section{Keywords}

Flexible Pavement, Geosynthetics, Deformation, Base Course

Subject Areas: Civil Engineering

\section{Introduction}

Major pavement deteriorations, similar to those observed in some Egyptian roads, especially in Delta region, result basically from permanent deformation in base course or subgrade soil. This deformation causes alligator or map cracking, chuck holes, settlement and undulations. In recent years, geosynthetics have been proposed and used to improve the performance of paved roadways. The major functions of geosynthetic materials are separation, reinforcement, filtration, drainage and liquid barrier. In providing reinforcement, the geosynthetic material 
structurally strengthens the pavement section by changing the response of the pavement to loading. Studies to date have found that incorporation of geosynthetics in flexible pavement provides a degree of performance improvement. A few studies have tried to quantify the benefits of geosynthetic reinforcement, but no firm conclusions can be drawn due to differences of results. Thus, an important need exists to quantify the benefits derived from stabilizing flexible pavements with geosynthetics and the conditions necessary for successful geosynthetic stabilization if an adequate cost comparison is to be made.

Fannin and Sigurdsson (1996) [1] conducted a field test on five reinforced and unreinforced sections of unpaved road. The reinforced sections (with geotextile or geogrid) obtained significant improvement on traffic ability. The improvement was the greatest for the thinner layers of base course $(25-30 \mathrm{~cm})$. Perkins (1999) [2] investigated the mechanistic response of geosynthetic-reinforced flexible pavement by using laboratory cyclic loading plate tests. The test results showed a significant improvement in the permanent deformation due to geosynthetic reinforcement. A 150 m long secondary road was observed by Appea and Al-Qadi (2003) [3] to quantify the benefits of geosynthetics. Analysis of Falling Weight Deflectometer (FWD) data indicated that the control section had the greatest rutting, followed by the geogrid stabilized section, while the geotextile stabilized section had the least amount of rutting. A laboratory research program was performed in a large steel box by Tingle and Jersey (2005) [4]. The results indicated that the use of a geotextile only provided the lowest permanent deformation, followed by sections including both the geotextile and geogrid. While the geogrid reinforced section resulted in similar permanent deformation as the control section.

The improvement in plastic surface deformation base course was investigated by Leng and Gabr (2002) [5] using two types of geogrids (BX1 and BX2). Higher modulus geogrid BX2 provided a better effect in reducing the plastic surface deformation. Demerchant et al. (2002) [6] performed plate load tests using a diameter plate (B) of $305 \mathrm{~mm}$ to study the effect of the geogrid depth (u) on subgrade modulus. The results indicate that the subgrade modulus decreases as u/B increases. Moreover, the most recent work by Gabr and Hart (2000) [7] reported that the elastic modulus decreased with increasing depth of the top geogrid layer. The results of laboratory and field tests performed by Mirafi Construction Products (2004) [8] indicated that geosynthetic type affected the pavement performance. The base course reduction (BCR) which expressed as a percentage savings of the unreinforced base thickness reached to $22 \%$ - $33 \%$ with using geotextile as base reinforcement while BCR reached to $30 \%-50 \%$ using geogrid. Hoe and Weng (2001) [9] produced that inclusion of geotextiles at the base layer-subgrade interface resulted in reduction in rut depth. Non-woven geotextiles showed a better rut improvement. Gurung (2003) [10] indicated that the use of geosynthatics increased the tensile strength and the tensile strength of a pavement reinforced using a geogrid was higher than using geotextile.

In granular material layers, the mechanism of rut depth reduction through geosynthetic reinforcement may be explained the Lateral movements are prevented by aggregate confinement, leading to increase in bulk stress, and aggregate layer stiffness, along with decrease in vertical stress on top of subgrade and vertical compressive strain reduction in lower half of base and in the subgrade. Over the period of pavement construction, there are usually two feasible alternatives for ground improvement, namely, soil stabilization and geosynthetic reinforcement. At times, some of the contractors prefer to use geosynthetics to reinforce subgrade [11]-[15]. An experimental program was presented in this research, aimed to study the effect of using geosynthetic reinforcement on the deformation characteristics of granular material that used as a base course. A pavement model containing a base course layer above a subgrade soil was prepared to simulate the field condition. The experimental program included many variables such as base course thickness, moisture contents, position of the geogrid layer and the geogrid opening size.

\section{Methodology}

An experimental program was carried out to investigate the influence of geothynthetic as reinforcement for the granular base layer of a flexible pavement constructed on silty subgrade. Plate loading test was performed as a control test to evaluate the deformation characteristics and bearing capacity of reinforced and unreinforced base course.

\subsection{Subgrade and Base Material}

A silty soil was used as subgrade. Crushed limestone was used as a base course. The grain size distributions as well as the grading limits according to AASHTO specifications for subgrade soil and base course are illustrated 
in Figure 1 and Figure 2. These soils were tested against Atterberg limits and maximum dry density. The physical and mechanical properties for subgrade and base course are presented in Table 1 and Table 2.

\subsection{Geothynthetic Material}

Two polyethylene geogrids (GR105 and GR420) with different opining size as shown in Figure 3 were used in this study. The geogrids thickness was $1.6 \mathrm{~mm}$, the rhomb opening areas were 105 and $420 \mathrm{~mm}^{2}$ respectively. As shown in Figure 3, the woven geotextile used in this study was locally manufactured as 45 tapes $/ 10 \mathrm{~cm}$. Table 3 shows the tensile strength, the maximum elongation and the modulus of elasticity for both geogrids and geotextile.

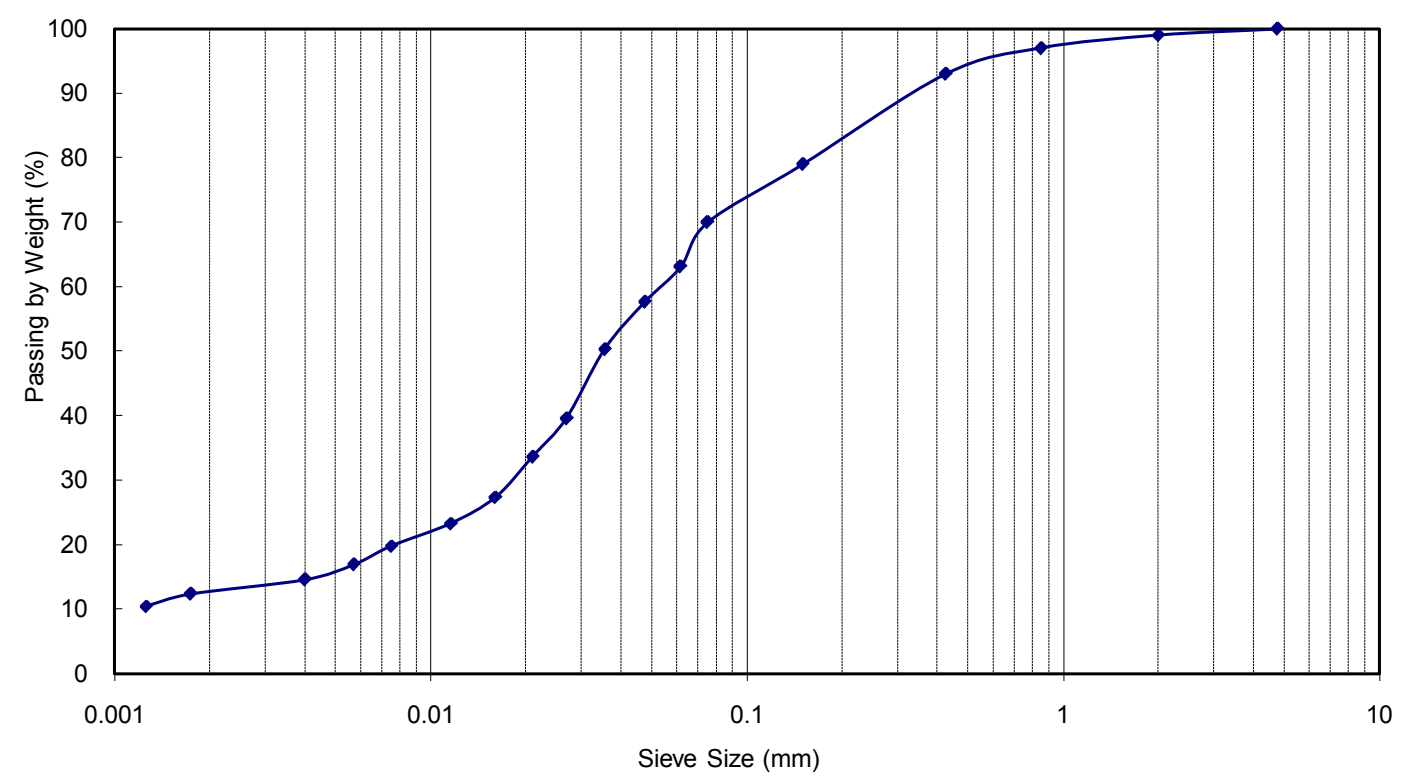

Figure 1. Grain size distribution for subgrade soil.

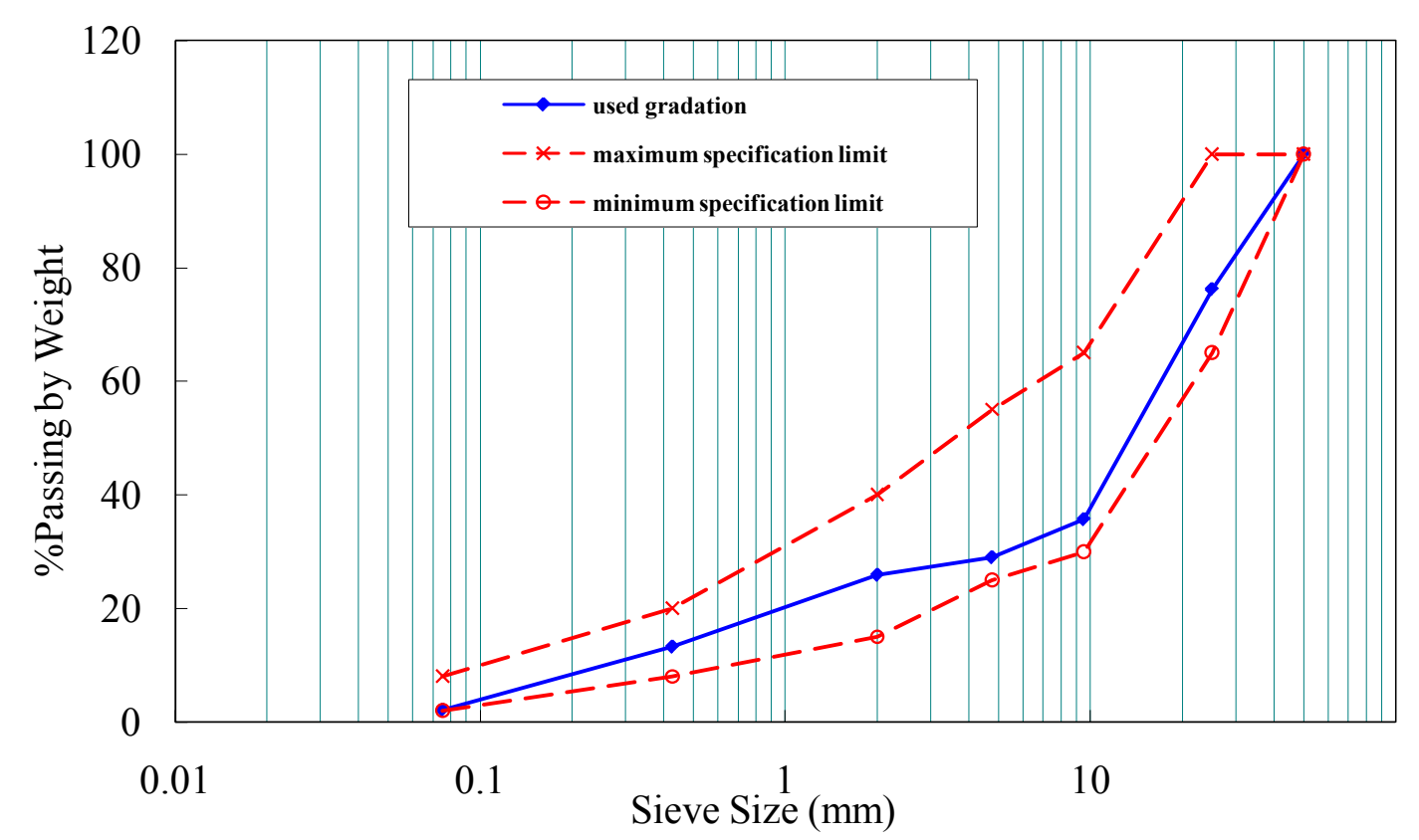

Figure 2. Grain size distribution for base course. 

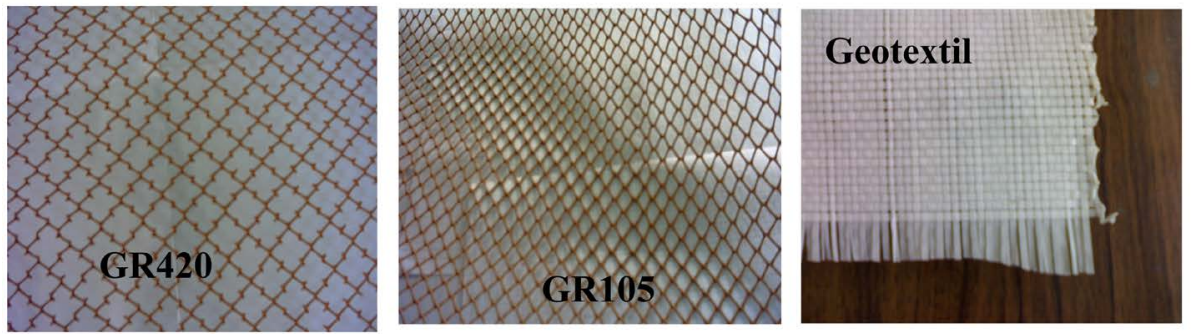

Figure 3. Geosynthetics used in study.

Table 1. Physical properties of subgrade soil and base course.

\begin{tabular}{ccc} 
Test & $\begin{array}{c}\text { Subgrade } \\
\text { soil }\end{array}$ & $\begin{array}{c}\text { Base } \\
\text { course }\end{array}$ \\
\hline Natural moisture content, $\%$ & 7.0 & 1.30 \\
Liquid Limit, $\%$ & 54.0 & 19.0 \\
Plastic Limit, $\%$ & 40.0 & 13.6 \\
Specific Gravity, gm $/ \mathrm{cm}^{3}$ & 2.68 & 2.65 \\
Loose density, gm $/ \mathrm{cm}^{3}$ & 1.33 & 2.12 \\
Maximum dry density, gm $/ \mathrm{cm}^{3}$ & 1.665 & 7.13 \\
Optimum moisture content, $\%$ & 16.0 & A-2-4 \\
AASHTO classification group & A-7-5 & GP \\
Unified classification group & MH & \\
\hline
\end{tabular}

Table 2. Mechanical properties of subgrade soil and base course.

\begin{tabular}{ccc}
\hline Test & $\begin{array}{c}\text { Subgrade } \\
\text { soil }\end{array}$ & $\begin{array}{c}\text { Base } \\
\text { course }\end{array}$ \\
\hline Cohesion $\left(\mathrm{N} / \mathrm{mm}^{2}\right)$ & 0.067 & 0.055 \\
Internal friction(o) & 19 & 23 \\
CBR (\%) & 8.8 & 97.0 \\
Unconfined comp. strength $\left(\mathrm{N} / \mathrm{mm}^{2}\right)$ & 0.165 & - \\
Modulus of elasticity $\left(\mathrm{N} / \mathrm{mm}^{2}\right)$ & 4.88 & 45.0 \\
\hline
\end{tabular}

Table 3. Properties of geogrid and geotextile.

\begin{tabular}{|c|c|c|c|}
\hline \multirow{2}{*}{ Geosynthetic Type } & \multicolumn{2}{|c|}{ Geogrid Type } & \multirow{2}{*}{ Geotextile } \\
\hline & GR105 & GR420 & \\
\hline Tensile strength $\left(\mathrm{kN} / \mathrm{m}^{\prime}\right)$ & 5.70 & 1.65 & 1.71 \\
\hline Elongation at Max. Load (\%) & 50 & 40 & 34 \\
\hline Modulus of Elasticity $\left(\mathrm{N} / \mathrm{mm}^{2}\right.$ ) & 62.63 & 22.9 & 34.9 \\
\hline
\end{tabular}

\subsection{The Test-Model Description}

The test-mode consisted of a square iron box $0.5 \mathrm{~m}$ wide by $0.5 \mathrm{~m}$ long and $0.5 \mathrm{~m}$ depth. This box divided into two halves containing two layers, $0.25 \mathrm{~m}$ depth subgrade, and limestone base course with 10,15 and $25 \mathrm{~cm}$ depths. The geosynthetic layer was placed at the interface between subgrade and base course and at different depths inside the base layer.

\subsection{Preparation of Tests}

Initially, the subgrade soil was prepared by adding optimum moisture content and compacted in five layers. 
Then, the geosynthetic was incorporated in the aggregate at a specified location. After that, the base course material was prepared by adding the optimum moisture content ( $8 \%$ ). Finally, the base course material was compacted in layers to obtain thickness of 10,15 and $25 \mathrm{~cm}$. At $25 \mathrm{~cm}$ base thickness for reinforced and unreinforced sections, four moisture contents were used ( $\mathrm{OMC}-2 \%, \mathrm{OMC}, \mathrm{OMC}+1.5 \%, \mathrm{OMC}+3 \%)$.

\subsection{Applied Vertical Pressure}

In this study, a contact pressure of $0.5 \mathrm{~N} / \mathrm{mm}^{2}\left(70 \mathrm{Ib} / \mathrm{in}^{2}\right)$ on asphalt surface layer was considered. BISAR-Linear elastic program was used to calculate the vertical stress at the surface of base course considering $5.0 \mathrm{~cm}$ asphalt wearing course and $5.0 \mathrm{~cm}$ asphalt binder coarse. The results indicated that vertical stress decreased to 0.35 $\mathrm{N} / \mathrm{mm}^{2}$ on the top of the base course.

\subsection{Plate Loading Test}

An initial static pressure of $0.0875 \mathrm{~N} / \mathrm{mm}^{2}$ was applied on the steel plate by using the loading head, the deflection was allowed to reach a maximum (waiting time about $20 \mathrm{~min}$.). As shown in Figure 4, the deflection was measured at the plate center as well as at the other points across the test-model center line. Then, the pressure increased to $0.35 \mathrm{~N} / \mathrm{mm}^{2}$ in $0.0875 \mathrm{~N} / \mathrm{mm}^{2}$ increments. The elastic modulus could be calculated as follows:

$$
E=\frac{1.38 p \cdot a}{w}
$$

where:

$E$ : modulus of elasticity (Mpa);

$p$ : uniform applied pressure (Mpa);

$a$ : radius of circular plate $(\mathrm{mm})$;

$w$ : deflection corresponding to the third load on the rigid plate (mm).

\section{Analysis of Experimental Results}

The plate loading test result for unreinforced $10 \mathrm{~cm}$ base course is shown in Figure 5. Static load test is applied and released three times on the base course material. Initially, it can be noticed that, the cumulative deformation of the first load cycle under the plate increased rapidly with increasing the vertical pressure on the plate. When the total load released and the material took a sufficient time to rebound, one part of vertical deflection was return and the residual part was remained. The returned division represents the elastic deformation, while the remained division symbolizes the plastic deformation. The rate of accumulated deformation became slightly in the second and third load cycle because of the base material has already deformed and compacted in the first load cycle.

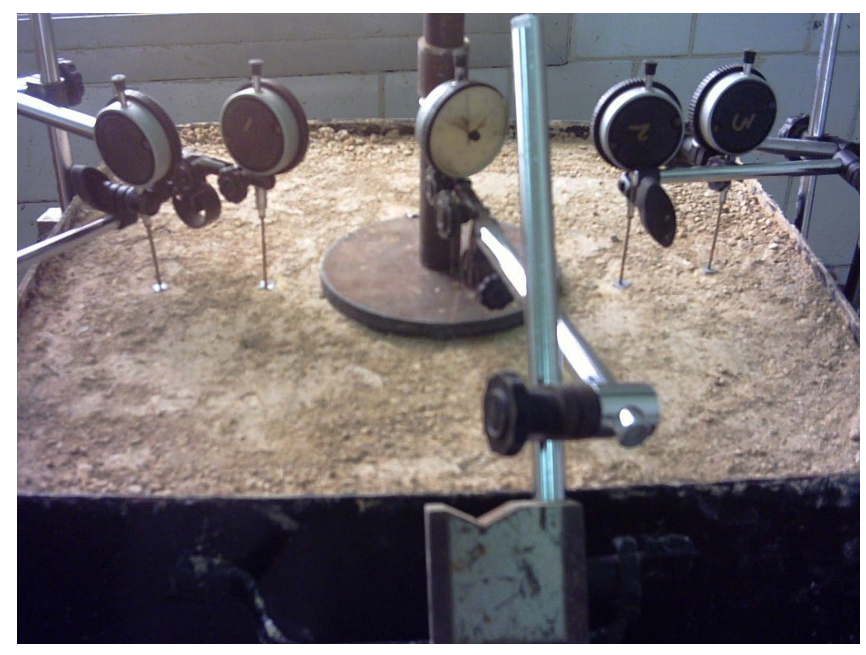

Figure 4. Plat loading test at $25 \mathrm{~cm}$ base thickness. 


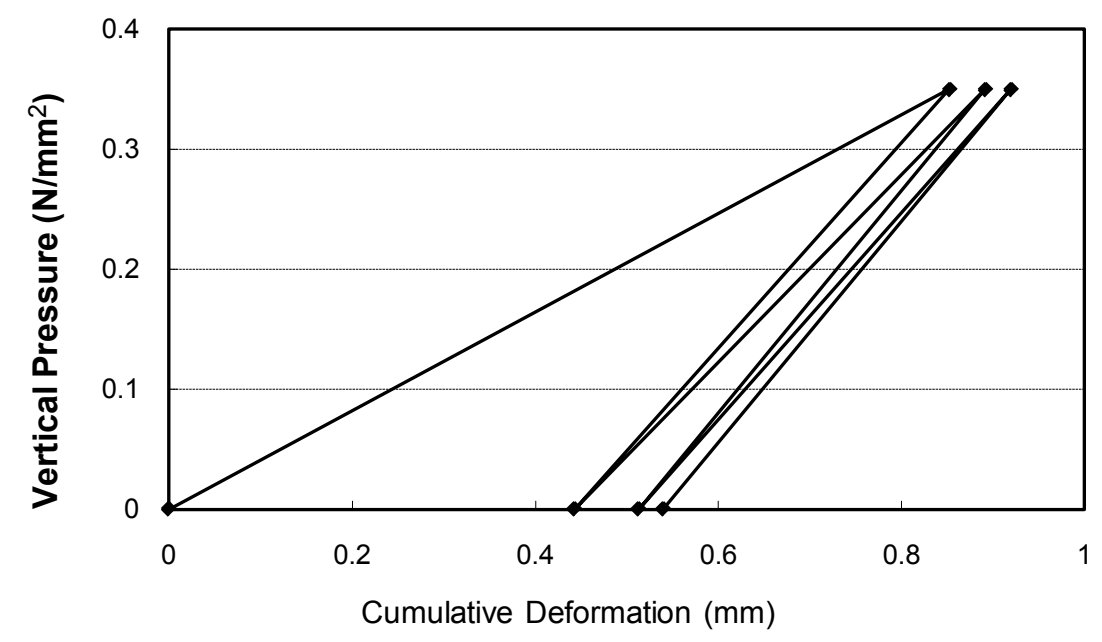

Figure 5. Cyclic loading test for unreinforced section.

The major objectives of this research were studying the influence of reinforcement, moisture contents of base course and geogrid fixation on elastic and plastic deformation. Moreover, the effect of base thickness, geogrid position and loading time on the deformation characteristics were investigated. For each base course thickness, reinforced sections (RS) and unreinforced sections (URS) were performed.

\subsection{Effect of Reinforcement on Modulus of Elasticity}

The amount of total deformation and the modulus of elasticity (E) values for each reinforcement case are shown in Tables 4-6 for each base thickness (h). The reinforcement depth (Dr) was investigated. Moreover, the reinforcement benefit ratio (RBR) was obtained as the reduction ratio in total deformation between the reinforced and unreinforced sections.

From Table 4, it could be noticed that all sections reinforced with GR105 gave a high negative RBR values. Based on this result, the geogrid (GR420) was chosen as reinforcement for the other base course thickness. Moreover, using geotextile alone hadn't any obvious effect on reduction of deformation. The fixed bottom reinforced section (BRS) provided higher modulus of elasticity; higher benefit ratio and lower plastic deformation than the middle reinforced section (MRS). For $25 \mathrm{~cm}$ base course the optimal reinforcement depth ratio within the base course which provided lower plastic deformation was obtained at ( $\mathrm{Dr} / \mathrm{h}=0.4$ to 0.6$)$. The double reinforced section DRS (bottom fixed layer and middle unfixed layer) achieved the lowest plastic deformation and the highest benefit ratio.

\subsection{Plastic and Elastic Deformation}

From the plate loading test results after the third loading cycle, elastic and plastic deformation could be calculated. Figure 6 correlates between deformation and distance along model center line for unreinforced $10 \mathrm{~cm}$ base course.

For all studied base thickness of unreinforced sections, the plastic deformation was found to be greater than the elastic deformation under the plate center. However, with increasing the distance from the plate center, the elastic deformation became greater than plastic deformation. For reinforced sections, it could be concluded that for base thickness less than $25 \mathrm{~cm}$, the plastic deformation became greater than elastic deformation at all points. For base thickness of $25 \mathrm{~cm}$, the plastic deformation became greater than the elastic deformation at all points at lower geogrid depth (Drlh less than or equal to 0.2) however, at higher geogrid depth (Drlh more than 0.2), the plastic deformation became greater than the elastic deformation under the plate center only.

\subsection{Effect of Loading Time on Accumulated Deformation}

The effect of loading time up to 48 hours on the accumulated deformation under a static load was performed for the URS and reinforced section (fixed BRS for $10 \mathrm{~cm}$ base course and DRS for 15 and $25 \mathrm{~cm}$ base course). A 
Table 4. Effect of reinforcement for $10 \mathrm{~cm}$ Base.

\begin{tabular}{|c|c|c|c|c|}
\hline Geogrid Type & Reinforcement Case & $\begin{array}{l}\text { Total Deformation } \\
(\mathrm{mm})\end{array}$ & $\mathrm{E}\left(\mathrm{N} / \mathrm{mm}^{2}\right)$ & $\begin{array}{c}\text { Benefit Ratio (\%) } \\
\text { (RBR) }\end{array}$ \\
\hline None & Unreinforced section & 0.92 & 42 & \\
\hline Geotextile & 1-Bottom unfixed geotextile & 0.91 & 42.46 & 1.08 \\
\hline GR105 & $\begin{array}{l}\text { 1-Composite reinforcement } \\
\text { 2-Bottom unfixed geogrid } \\
\text { 3-Middle unfixed geogrid }\end{array}$ & $\begin{array}{l}1.94 \\
2.04 \\
1.52\end{array}$ & $\begin{array}{c}19.9 \\
18.94 \\
25.42\end{array}$ & $\begin{array}{l}-110.8 \\
-121.7 \\
-65.2\end{array}$ \\
\hline GR420 & $\begin{array}{l}\text { 1-Bottom unfixed geogrid } \\
\text { 2-Bottom fixed geogrid } \\
\text { 3-Middle unfixed geogrid }\end{array}$ & $\begin{array}{l}0.88 \\
0.85 \\
0.96\end{array}$ & $\begin{array}{c}43.9 \\
45.46 \\
40.25\end{array}$ & $\begin{array}{c}4.34 \\
7.6 \\
-4.3\end{array}$ \\
\hline
\end{tabular}

Table 5. Effect of Reinforcement for $15 \mathrm{~cm}$ Base.

\begin{tabular}{|c|c|c|c|c|}
\hline Geogrid Type & Reinforcement Case & $\begin{array}{l}\text { Total Deformation } \\
(\mathrm{mm})\end{array}$ & $\mathrm{E}\left(\mathrm{N} / \mathrm{mm}^{2}\right)$ & Benefit Ratio (\%) \\
\hline None & Unreinforced Section (URS) & 0.85 & 45.45 & \\
\hline Geotextile & 1-Bottom Unfixed Geotextile & 0.89 & 43.41 & -4.7 \\
\hline GR420 & $\begin{array}{l}\text { 1-Bottom Unfixed Geogrid } \\
\text { 2-Bottom Fixed Geogrid } \\
\text { 3-Composite Reinforcement } \\
\text { 4-Middle Unfixed Geogrid } \\
\text { 5-Middle Fixed Geogrid } \\
\text { 6-Two Layers Reinforcemend }\end{array}$ & $\begin{array}{c}0.82 \\
0.74 \\
0.812 \\
0.792 \\
0.785 \\
0.67\end{array}$ & $\begin{array}{l}47.12 \\
52.21 \\
47.58 \\
48.21 \\
49.22 \\
57.67\end{array}$ & $\begin{array}{c}3.53 \\
12.94 \\
4.47 \\
6.82 \\
7.65 \\
21.18\end{array}$ \\
\hline
\end{tabular}

Table 6. Effect of reinforcement for $25 \mathrm{~cm}$ base.

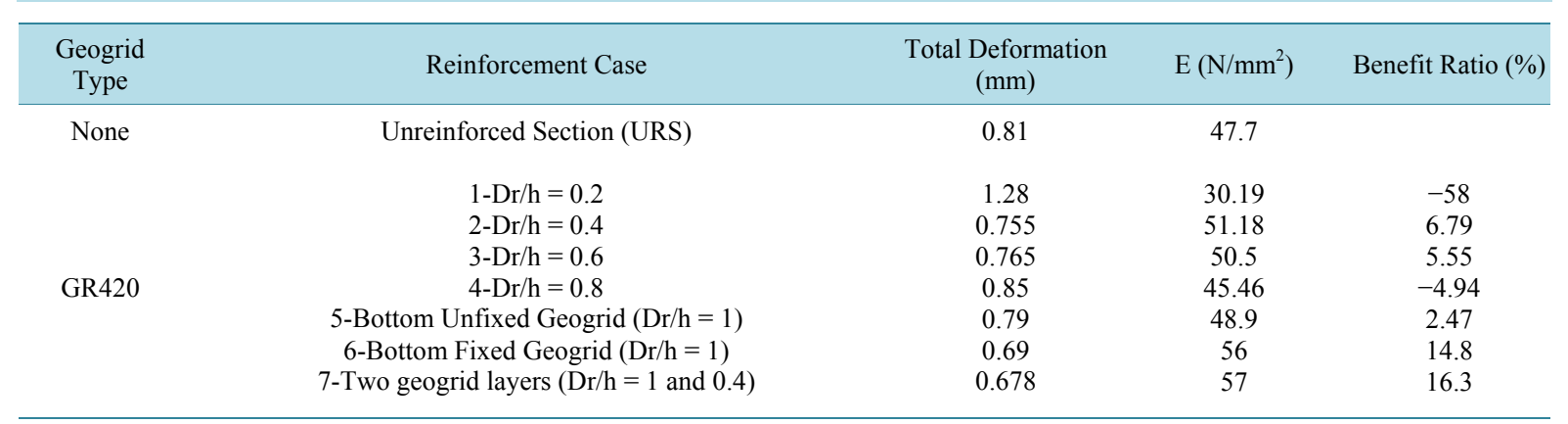

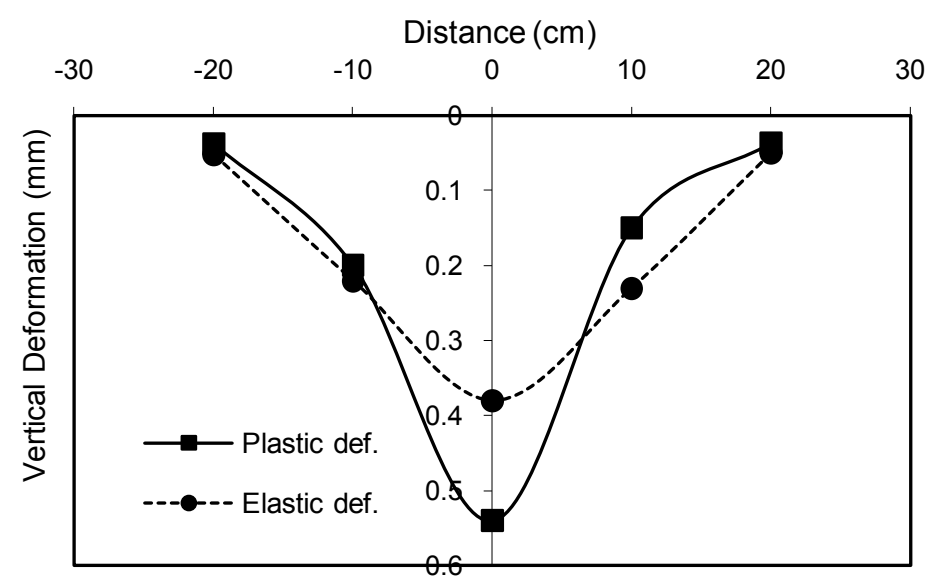

Figure 6. Deformation along the center line for URS. 
great influence for reinforcement was observed where the accumulated deformation curves for reinforced sections were a semi constant or increased slightly with increasing the loading time especially at the end of the test period. Summary of the deformation progress under the plate center and at distances of 10 and $20 \mathrm{~cm}$ for $10 \mathrm{~cm}$ base course are represented in Figure 7.

\subsection{Effect of Base Thickness on Elastic Modulus}

Three base course thickness 10, 15 and $25 \mathrm{~cm}$ and additional unreinforced thickness of $40 \mathrm{~cm}$ were used. As shown in the previous results and in Figure 8, it could be indicated that the plastic deformation decreased and the modulus of elasticity of base course increased as the base course thickness increased. On the other hand, the fixed bottom reinforcement section performed better than it for unfixed RS at all studied base thickness.

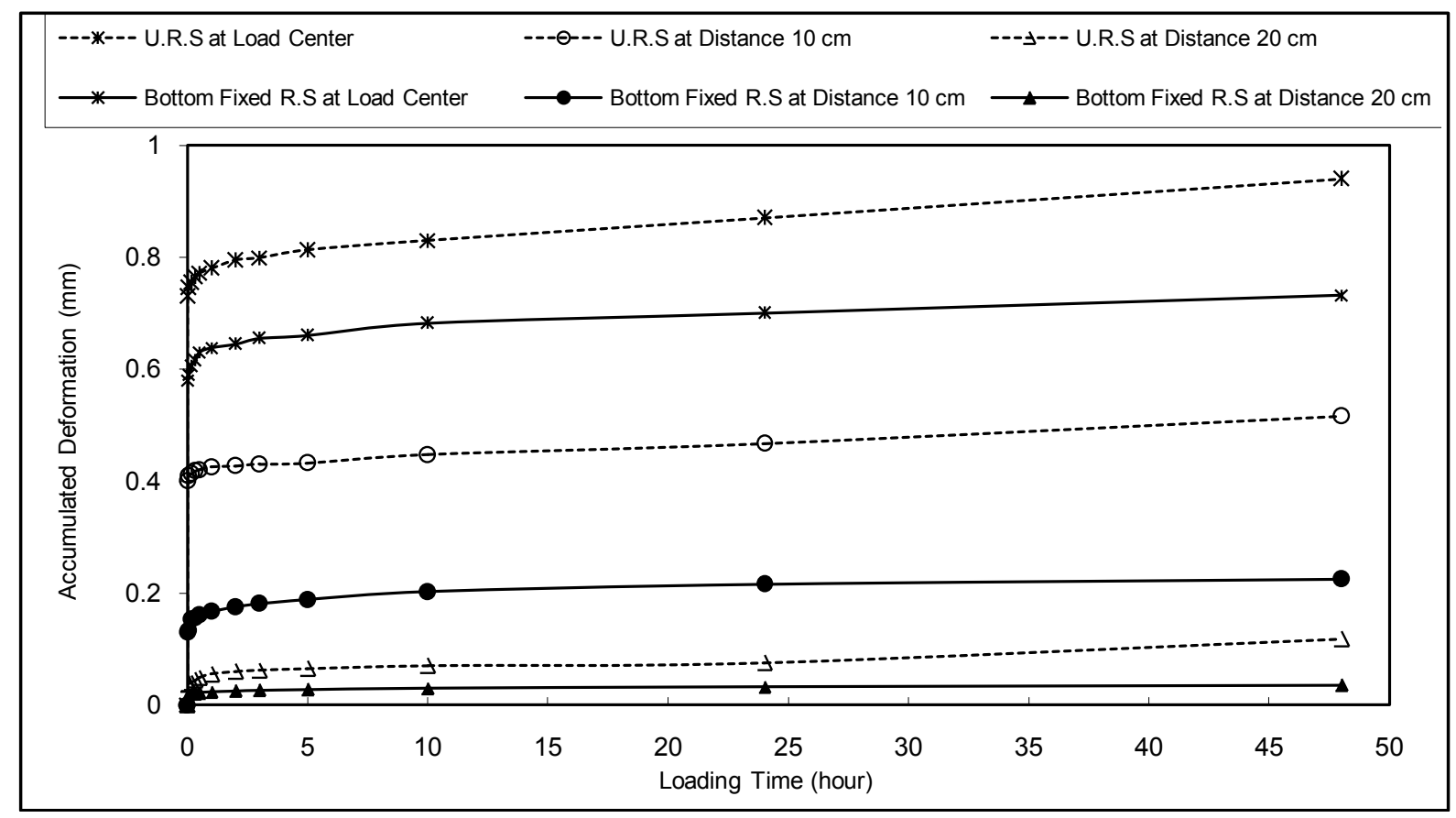

Figure 7. Effect of loading time $10 \mathrm{~cm}$ base section.

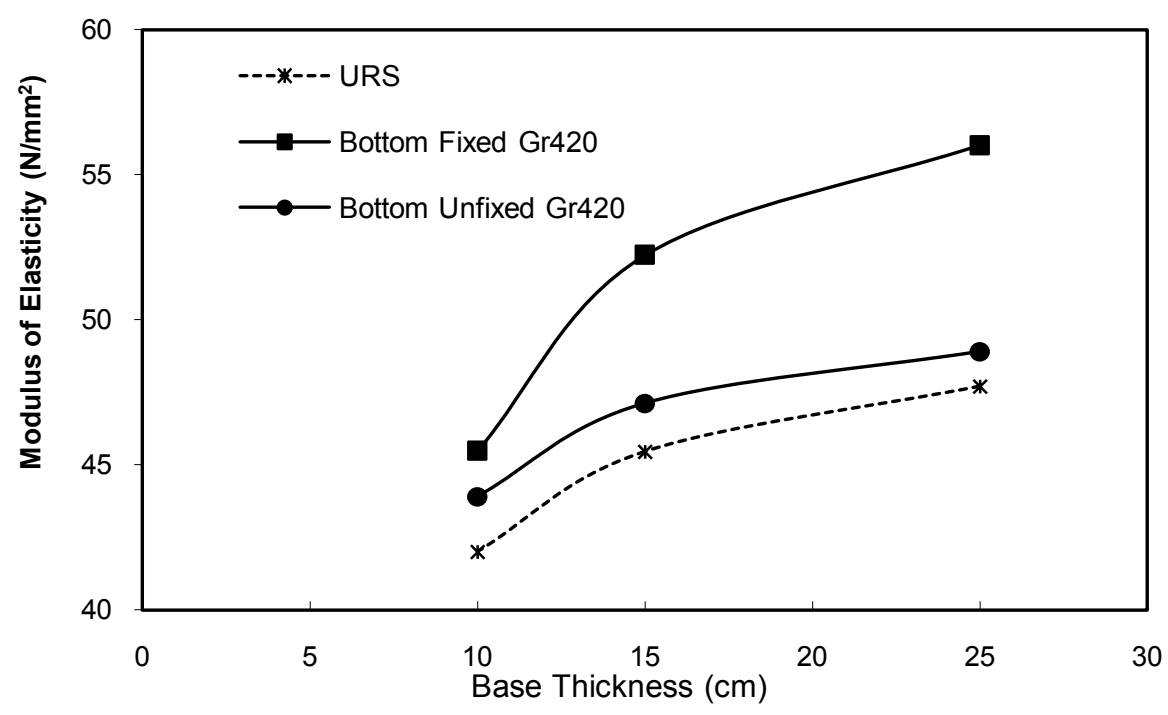

Figure 8. Effect of base thickness on the modulus of elasticity. 


\subsection{Effect of Moisture Content for $25 \mathrm{~cm}$ Base Sections}

From Table 7 and Figure 9 it could be observed that with increasing moisture content, the reinforcement benefit ratios (RBR) decreased. The highest modulus of elasticity (E) obtained at OMC where the improvement decreased with increasing moisture contents. As shown in Figure 10, the ratio of plastic deformation to the total accumulated deformation (PDR) for reinforced section was lower than it for unreinforced section for all moisture contents especially above OMC.

\subsection{Effect of Moisture Content on Plastic \& Elastic Deformation}

Figure 11 illustrates the effect of reinforcement on elastic and plastic deformation for OMC. For all moisture contents, the plastic deformation was found to be greater than elastic deformation under the plate center. However, with increasing the distance from the plate center, the elastic deformation became greater than plastic deformation at $6 \%$ and $8 \%$ moisture content. While at $9.5 \%$ and $11 \%$, the plastic deformation became higher than elastic deformation at all points.

Table 7. Effect of moisture content on reinforcement benefit ratio.

\begin{tabular}{cccccccccc}
\hline Moisture content (\%) & \multicolumn{2}{c}{6} & \multicolumn{2}{c}{8 (OMC) } & \multicolumn{2}{c}{9.5} & & 11 \\
\hline Section condition & URS & RS & URS & RS & URS & RS & URS & RS \\
RBR (\%) & --- & 23.5 & --- & 16.3 & --- & 12.5 & --- & 6.75 \\
\hline
\end{tabular}

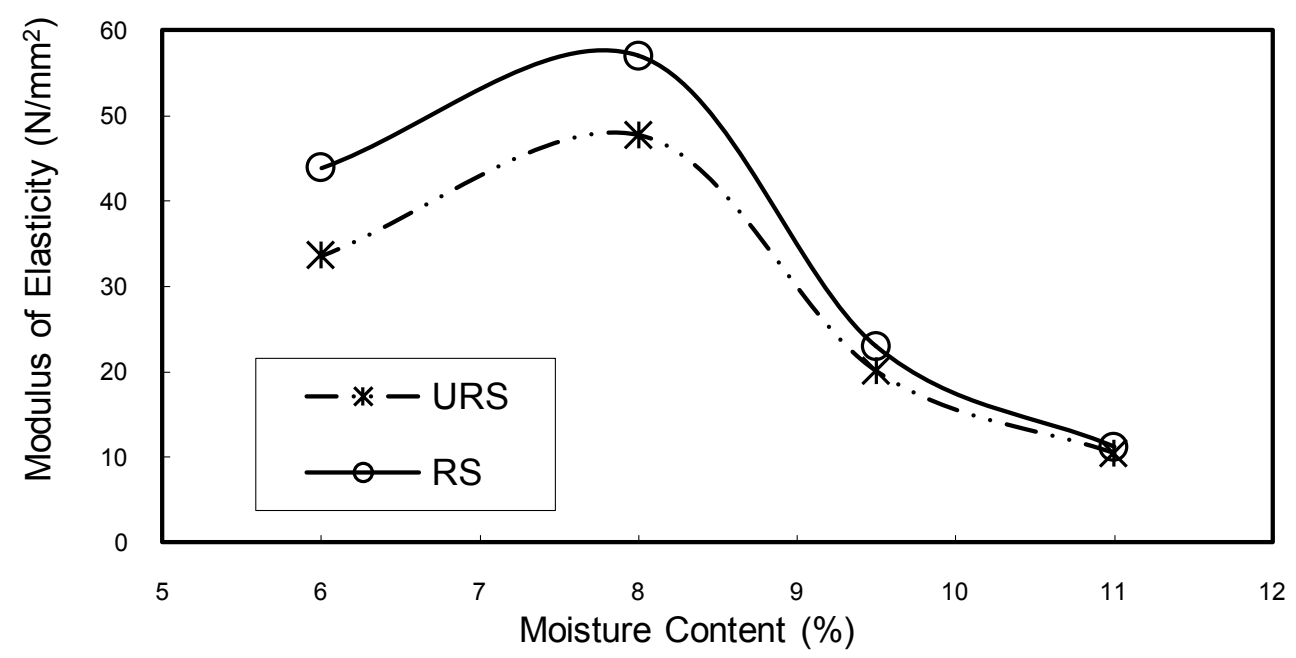

Figure 9. Effect of moisture content on modulus of elasticity.

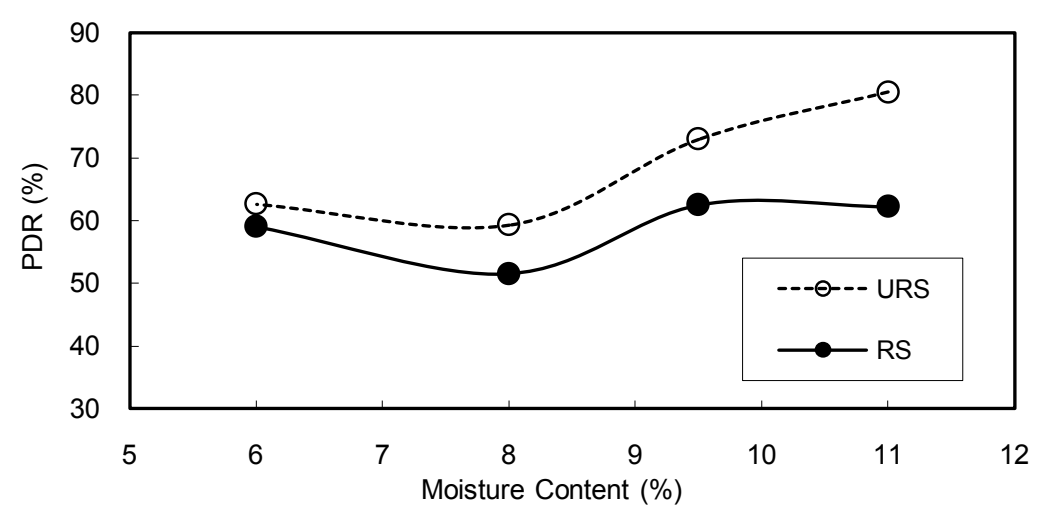

Figure 10. Effect of moisture content on plastic deformation ratio. 


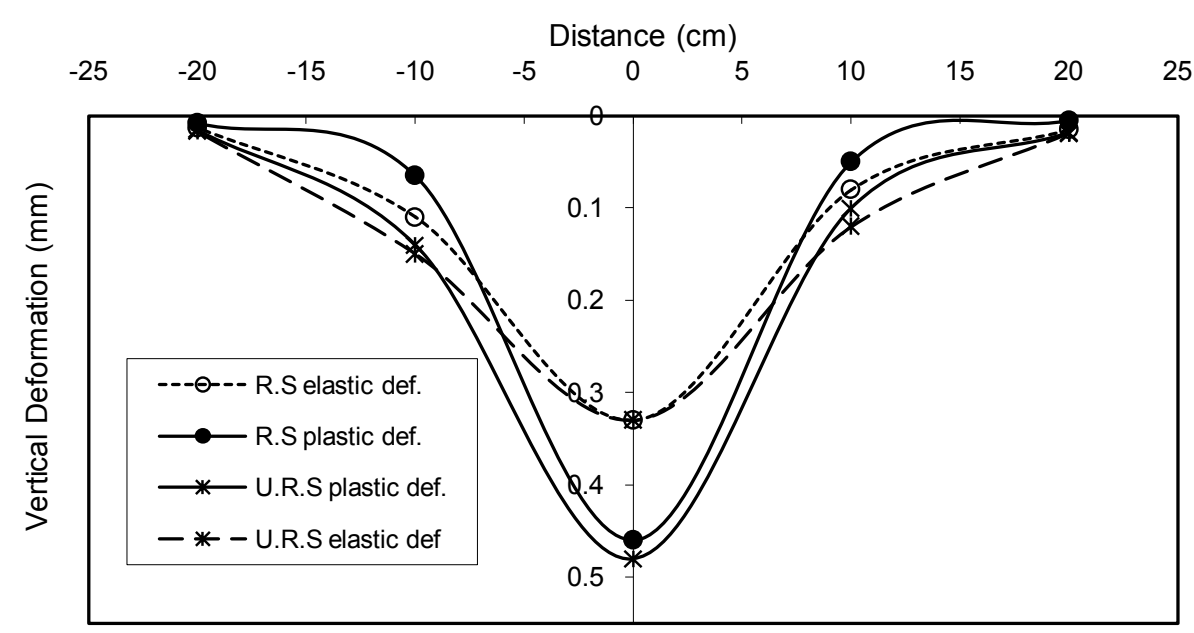

Figure 11. Plastic and elastic deformation at OMC of $8 \%$.

\subsection{Effect of Reinforcement on Base Thickness Saving}

Using geogrid GR420 as reinforcement had the greatest effect on the reduction of base thickness (BCR) and the plastic deformation reduction ratio (DRR) where the base course thickness of $15 \mathrm{~cm}$ could be reduced to $10 \mathrm{~cm}$ $(\mathrm{BCR}=33 \%, \mathrm{DRR}=14 \%)$ if reinforced with fixed bottom geogrid. Moreover, the unreinforced section of 25 $\mathrm{cm}$ base thickness could be reduced to $15 \mathrm{~cm}(\mathrm{BCR}=40 \%)$ if it is reinforced with fixed BRS or DRS to achieve $\mathrm{DRR}=8.3 \%$ or $21.7 \%$ respectively. Furthermore, the unreinforced section of $40 \mathrm{~cm}$ base thickness could be reduced to $15 \mathrm{~cm}$ (BCR $=62.5 \%$, DRR of $14.5 \%)$ if it is reinforced with DRS, and could be reduced to $25 \mathrm{~cm}$ $(\mathrm{BCR}=37.5 \%)$ if reinforced with fixed BRS or DRS to achieve DRR of $5.7 \%$ or $12.7 \%$ respectively.

\section{Conclusions}

1) The geogrid GR420 was the optimal type to be used as reinforcement for base course where a great reduction of plastic deformation was obtained. Moreover, Fixation of the geogrid edges had a great effect on reduction of accumulative plastic deformation of base course.

2) The bottom reinforced section (BRS) was better than middle reinforced section (MRS). For $25 \mathrm{~cm}$ base course the optimal reinforcement depth ratio was obtained at $(\mathrm{Dr} / \mathrm{h}=0.4$ to 0.6$)$. By using geogrid GR420 the unreinforced section of $40 \mathrm{~cm}$ could be reduced to $15 \mathrm{~cm}(\mathrm{BCR}=62.5 \%$, DRR of $14.5 \%)$ if it was reinforced with DRS.

3) For reinforced base course less than $25 \mathrm{~cm}$ thickness, the plastic deformation became greater than elastic deformation at all points. The same occurred for $25 \mathrm{~cm}$ thickness at lower geogrid depth (Drlh less than or equal to 0.2 ). On another side, the accumulated deformation curves for reinforced sections were a semi constant with increasing the loading time up to 48 hours especially at the end of the test period.

4) With increasing moisture content, the reinforcement benefit ratio RBR decreased. The ratio of plastic deformation (PDR) for reinforced section was lower than it for unreinforced section for all moisture contents especially above OMC. Moreover, for all moisture contents, the plastic deformation was greater than elastic deformation under the plate center only. The same occurred at other points for $9.5 \%$ and $11 \%$ moisture content. While, the opposite occurred at $6 \%$ and $8 \%$ moisture content.

\section{References}

[1] Fannin, R.J. and Sigurdsson, O. (1996) Field Observations on Stabilization of Unpaved Roads with Geosynthetics. Journal of Geotechnical Engineering, ASCE, 122, 544-553. http://dx.doi.org/10.1061/(ASCE)0733-9410(1996)122:7(544)

[2] Perkins, S.W. (1999) Mechanical Response of Geosynthetic-Reinforced Flexible Pavements. Thomas Telford Journals, Geosynthetics International, 6, 347-382. http://dx.doi.org/10.1680/gein.6.0157

[3] Appea, A. and Al-Qadi, I. (2000) Assessment of FWD Deflection Data in Stabilized Flexible Pavements. The 79th 
Annual Transportation Research Board Meeting, Washington DC, January 2000, 19-25.

[4] Tingle, S. and Jersey, S.R. (2005) Cyclic Plate Load Testing of Geosynthetic-Reinforced Unbound Aggregate Roads. The 84th Annual Transportation Research Board Meeting, Washington DC, January 2005, 60-69. http://dx.doi.org/10.3141/1936-08

[5] Leng, J. and Gabr, M.A. (2005) Numerical Analysis of Stress-Deformation Response in Reinforced Unpaved Road Sections. Thomas Telford Journals, Geosynthetics International, 12, 111-119. http://dx.doi.org/10.1680/gein.2005.12.2.111

[6] Demerchant, M.R., Valsangkar, A.J. and Schriver, A.B. (2002) Plate Load Tests on Geogrid-Reinforced Expanded Shale Lightweight Aggregate. Geotextiles and Geomembranes, 20, 173-190. http://dx.doi.org/10.1016/S0266-1144(02)00006-7

[7] Gabr, M.A. and Hart, J.H. (2000) Elastic Modulus of Geogrid Reinforced Sand Using Plate Load Tests. Geotechnical Testing Journal, ASTM, 23, 245-250. http://dx.doi.org/10.1520/GTJ11049J

[8] Mirafi Construction Products (2004) Geosynthetic Reinforcement of the Aggregate Base/Subbase Courses of Pavement Structures. Revision 2. www.mirafi.com

[9] Defence Science and Technology Agency (DSTA) (2004) Geotextiles in Unpaved Roads: Separation or Reinforcement. Singapore.

[10] Gurung, N. (2003) A Laboratory Study on the Tensile Response of Unbound Granular Base Road Pavement Model Using Geosynthetics. Geotextiles and Geomembranes, 21, 59-68. http://dx.doi.org/10.1016/S0266-1144(02)00033-X

[11] Sina, M.M. and Mohamed, R.K. (2014) Improving Rutting Resistance of Pavement Structures Using Geosynthetics: An Overview. The Scientific World Journal, Hindawi Publishing Corporation, Cairo.

[12] Han, J., Zhang, Y. and Parsons, R. (2011) Quantifying the Influence of Geosynthetics on Performance of Reinforced Granular Bases in Laboratory. Geotechnical Engineering, 1, 75.

[13] Kim, Y. and Park, T.-S. (2013) Reinforcement of Recycled Foamed Asphalt Using Short Polypropylene Fibers. Advances in Materials Science and Engineering, 2012, Article ID: 903236. http://dx.doi.org/10.1155/2013/903236

[14] Bertuliene, L., Oginskas, R. and Bulevicius, M. (2011) Research of Rut Depth in Asphalt Pavements Reinforced with Geosynthetic Materials. Proceedings of the 8th International Conference Environmental Engineering, 19-20 May 2011, Vilnius, 1039-1045.

[15] Helstrom, C.L., Humphrey, D.N. and Hayden, S.A. (2007) Geogrid Reinforced Pavement Structure in a Cold Region. Proceedings of the 13th International Conference on Cold Regions Engineering, Orono, July 2007, 1-12. 